\title{
Effects of Austenite Grain Size on $\varepsilon$ Martensitic Transformation in Fe-15mass\%Mn Alloy
}

\author{
Setsuo Takaki, Hideshi Nakatsu ${ }^{\dagger}$ and Youichi Tokunaga \\ Department of Materials Science and Engineering, Faculty of Engineering, \\ Kyushu University, Fukuoka 812, Japan
}

\begin{abstract}
The effect of austenite $(\gamma)$ grain size on the morphology of $\varepsilon$ martensite $(\varepsilon)$ and the transformation from $\gamma$ to $\varepsilon$ has been investigated by means of optical microscopy, transmission electron microscopy and X-ray analysis in Fe- 15 mass \% Mn alloy, whose $\gamma$ grain size was controlled between 1 and $130 \mu \mathrm{m}$ by the reversion treatment of deformation induced bcc martensite to $\gamma$. With refining $\gamma$ grain size, the formation of $\varepsilon$ tends to be suppressed and the starting temperature of $\gamma-\varepsilon$ transformation is also lowered. In the grain size range below $30 \mu \mathrm{m}$, the transformation is markedly suppressed.

In small $\gamma$ grains below $30 \mu \mathrm{m}$, one variant of $\varepsilon$ plates go through a $\gamma$ grain from one grain boundary to the other of the opposite side. When the size of $\gamma$ grains is sufficiently larger than $30 \mu \mathrm{m}$, however, the microstructure changes to a different one in which a lot of $\varepsilon$ plates intersect each other within a large $\gamma$ grain. In this case, $\varepsilon$ plates were formed on four $\{111\}_{\gamma}$ planes in the Shoji-Nishiyama relation. The growing process of $\varepsilon$ plates in a large $\gamma$ grain is as follows: When one $\varepsilon$ plate grows to a certain critical size, branching takes place at the tip of pre-formed $\varepsilon$ plate in order to reduce the elastic coherent stress at $\gamma / \varepsilon$ interface, so that austenite can smoothly transform to $\varepsilon$ by the chain reaction through branching of $\varepsilon$. When the $\gamma$ grain size was not large enough to the critical size of $\varepsilon$ plate, the growth of $\varepsilon$ should be stopped by grain boundaries before the branching of $\varepsilon$ takes place. This leads to the suppressive effect in $\gamma-\varepsilon$ transformation by $\gamma$ grain refining.
\end{abstract}

(Received February 1, 1993)

Keywords: high manganese steel, austenite, epsilon martensite, martensitic transformation, grain refining, microstructure

\section{Introduction}

The grain size is one of the important factors which affect the behavior of martensitic transformations. Especially, the relationship between austenite $(\gamma)$ grain size and the transformation from $\gamma$ to bcc martensite $\left(\alpha^{\prime}\right)$ has enthusiastically been investigated in terms of the hardenability of steels in the quenching technique. The researches for $\mathrm{Fe}-\mathrm{Cr}-\mathrm{Ni}^{(1)}$ and $\mathrm{Fe}-\mathrm{Ni}-\mathrm{C}^{(2)(3)}$ alloys, which are used for low temperature applications and shape memory materials, have indicated a suppressive effects by grain refining in martensitic transformations. That is, as the austenite grain size becomes smaller, the amount of $\alpha^{\prime}$ is decreased and also the starting temperature of transformation $\left(M_{\mathrm{s}}\right)$ is slightly lowered. The reasons are explained as follows: Grain boundaries are relatively stable to the nucleation of $\alpha^{\prime}$ because the atoms around grain boundaries are free from the binding of neighbor atoms and besides the growth of $\alpha^{\prime}$ nucleated within an austenite grain is stopped by grain boundaries ${ }^{(4)}$. On the other hand, the opposite idea has been proposed in the study of Ti-Ni alloys ${ }^{(5)}$ : Since the total grain boundary area is increased with grain refining, the number of nucleation sites for the martensitic transformation is also increased and hence the $M_{\mathrm{s}}$ is raised. These facts suggest that the influences of the grain boundary on martensitic transformations are not simple and that the effect of grain refining should appear in different ways depending on the mechanism and driving force in martensitic transformations and so on.

Recently, high manganese steels have been developed as the structural material used below the liquid nitrogen temperature, for they have stable non-magnetic nature and excellent mechanical properties at such low temperatures. The stacking fault energy of these high manganese steels is essentially so small that the martensite with hcp structure $(\varepsilon)$ is easy to form from $\gamma$ through stacking faults prior to the transformation to $\alpha^{\prime}$. The mechanism of the $\gamma-\varepsilon$ transformation is entirely different from that of the $\gamma-\alpha^{\prime}$ transformation, and the driving force needed for the $\gamma-\varepsilon$ transformation is also considerably small ${ }^{(6)}$. The transformation from $\gamma$ to $\varepsilon$ is not only useful for the shape memory phenomenon ${ }^{(7)}$ but also very influential to the mechanical properties of high manganese steels $^{(8)}$. Although the size of austenite grains must be an important factor even in $\gamma-\varepsilon$ transformation, but the details have not been cleared yet.

In this paper, the effect of austenite grain size on the $\gamma-\varepsilon$ transformation was discussed in connection with the morphology and crystallography of $\varepsilon$ for a $\mathrm{Fe}-15$ mass\%Mn binary alloy, in which a lot of athermal $\varepsilon$ can be formed ${ }^{(9)}$ and austenite grain size can widely be controlled between $1 \sim 130 \mu \mathrm{m}$ by the reversion treatment of deformation induced $\alpha^{\prime(10)}$. 


\section{Experimental Procedure}

\section{Materials and heat treatment}

An Fe-15 mass \% Mn alloy of $1.5 \mathrm{~kg}$ was prepared by high frequency induction melting from industrial pure iron $(0.008 \% \mathrm{C}, \quad 0.005 \% \mathrm{Si}, \quad 0.025 \% \mathrm{Mn}, \quad 0.008 \% \mathrm{P}$, $0.011 \% \mathrm{~S}$ in mass \%) and metallic manganese. Pure iron was first molten in a vacuum of $0.1 \mathrm{~Pa}$ and then metallic manganese was added in argon gas atmosphere. The chemical composition of alloy used was $14.69 \% \mathrm{Mn}$, $0.004 \% \mathrm{C}, 0.012 \% \mathrm{Si}, 0.011 \% \mathrm{P}, 0.012 \% \mathrm{~S}$. The ingot of $28 \mathrm{~mm}$ thick was homogenized at $1473 \mathrm{~K}$ for $36 \mathrm{ks}$, hotrolled to $12 \mathrm{~mm}$ thick, and then solution-treated at 1473 $\mathrm{K}$ for $1.8 \mathrm{ks}$. The $12 \mathrm{~mm}$ thick steel plate was subjected to $70 \%$ cold rolling at room temperature in order to make the $\gamma$ structure change to full $\alpha^{\prime}$ by the deformation induced transformation. The materials were machined at this stage and then annealed $600 \mathrm{~s}$ at several temperatures above $873 \mathrm{~K}$, where $\alpha^{\prime}$ entirely reverts to the $\gamma$ structure. The austenite grain size was controlled by varying the annealing temperature.

\section{Examinations}

The behavior of the $\gamma-\varepsilon$ transformation was examined with a differential scanning calorimeter (DSC) during air cooling from several annealing temperatures. The $M_{\mathrm{s}}$ point was defined as the temperature where the DSC curve deviates from the base line owing to the exothermic $\gamma-\varepsilon$ transformation.

The volume fraction of $\varepsilon$ and $\gamma$ was calculated from the $\gamma / \varepsilon$ ratio in the integrated intensity of X-ray diffraction lines. Besides, quantitative analysis of $\alpha^{\prime}$, which was athermally induced a little bit in specimens with large austenite grains, was performed by the measurement of saturation magnetization (Is: $\mathrm{Wb} / \mathrm{m}^{2}$ ) with a direct current magnetometer for the test pieces of $4 \times 1 \times 30 \mathrm{~mm}^{(11)}$. Since the Is value is proportional to the volume fraction of ferro-magnetic $\alpha^{\prime}$, the volume fraction of $\alpha^{\prime}$ can be obtained from the following eq. (1):

$$
\alpha^{\prime}(\mathrm{vol} \%)=\left(\mathrm{Is} / \mathrm{Is}^{*}\right) \times 100
$$

where Is* is that for the specimen with full $\alpha^{\prime}$ structure. The value of Is* is so sensitive to chemical compositions that we previously confirmed the relationship between manganese content and the Is* value:

$$
\text { Is }^{*}=2.125-0.0264 \times(\operatorname{mass} \% \mathrm{Mn})
$$

Microstructures of the specimens were observed with an optical microscope and a $200 \mathrm{kV}$ transmission electron microscope (TEM). Specimens were prepared by $2 \%$ nital etching for optical observation and by jet electropolishing method with $10 \%$ perchloric acid and $90 \%$ acetic acid solution for TEM observation. The mean austenite grain size of specimens was determined by comparing the observed microstructure with the ASTM standard for the $\gamma$ grain size, and estimated as the nominal size in dodecahedron grains ${ }^{(12)}$. The relation in morphology between the $\varepsilon$ martensite and the austenite grain size was determined for equi-axial grains excepting twins, and the size of equi-axial grains was obtained by the line analysis on micrographs.

\section{Experimental Results}

\section{Effect of austenite grain size on the behavior of $\varepsilon$ martensitic transformation}

Figure 1 shows the relation between austenite grain size and annealing temperature. The reversion finishing temperature to austenite of martensite, which has been induced by $70 \%$ cold rolling, is around $873 \mathrm{~K}$ and the grain size of reversed austenite is as small as about $1 \mu \mathrm{m}$. With raising the annealing temperature, the austenite grain size becomes larger. So we can easily control the grain size from $1 \mu \mathrm{m}$ to $130 \mu \mathrm{m}$ by varying the annealing temperature between 873 and $1473 \mathrm{~K}$.

Figure 2 indicates the relation between austenite grain size and volume fractions of $\varepsilon$ and $\alpha^{\prime}$ formed athermally. As the grain size becomes smaller, the amount of $\varepsilon$ is abruptly decreased in the grain size range under $30 \mu \mathrm{m}$. Besides for $\alpha^{\prime}$ martensite, the transformation was also almost suppressed in the grain size range under $30 \mu \mathrm{m}$,

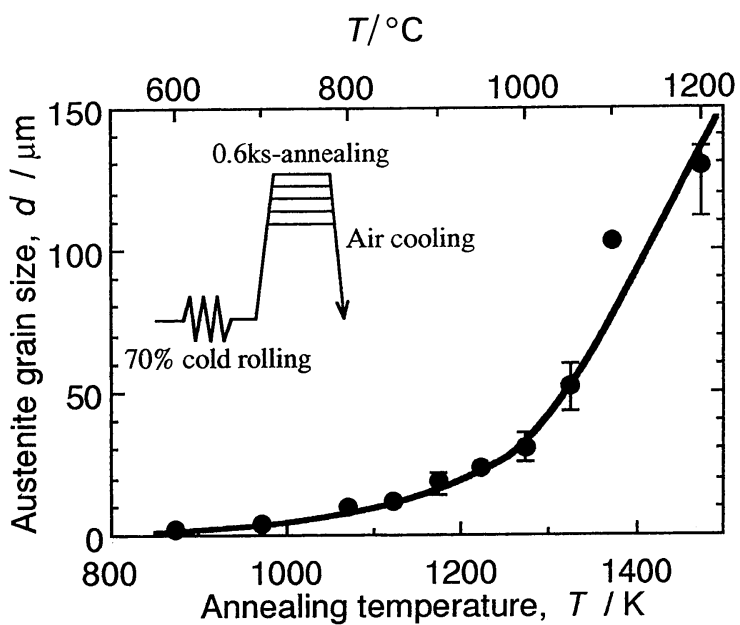

Fig. 1 Relation between annealing temperature and austenite grain size.

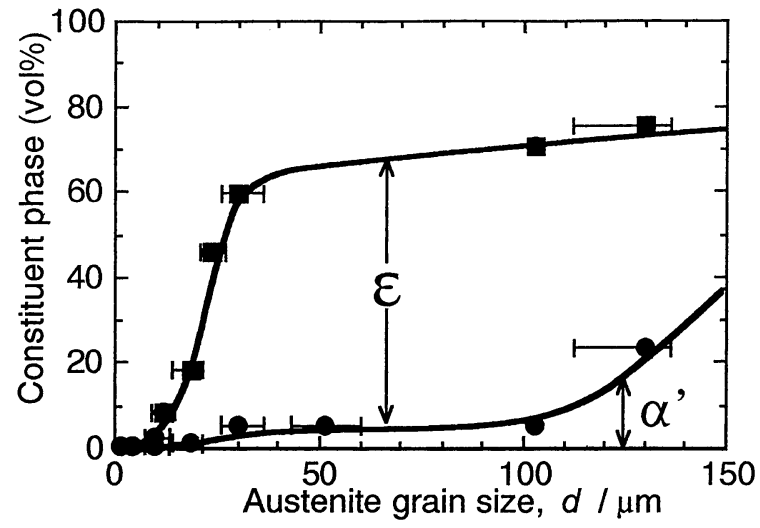

Fig. 2 Effect of austenite grain size on the volume fraction of $\varepsilon$ and $\alpha^{\prime}$ martensites which have been formed during cooling from the selected annealing temperatures between 873 and $1473 \mathrm{~K}$. 
while more than $5 \%$ of $\alpha^{\prime}$ was formed above $30 \mu \mathrm{m}$. Since most of $\alpha^{\prime}$ particle was observed within $\varepsilon$ phase at the intersections of platelet $\varepsilon$, the formation of $\alpha^{\prime}$ must also be related to the formation of $\varepsilon$ through the mechanism of $\gamma-\varepsilon-\alpha^{\prime(13)}$. Figure 3 shows DSC curves of specimens with different austenite grain sizes. Examinations were performed during cooling after the annealing treatment that gives several austenite grain size to the specimens used. Exothermic reaction by the $\gamma-\varepsilon$ transformation starts from around $450 \mathrm{~K}$ and the starting temperature $\left(M_{s}^{\gamma-\varepsilon}\right)$ slightly shifts to the lower temperature side, when the austenite grain size is smaller than $30 \mu \mathrm{m}$. The amount of heat also decreases with refining austenite grains in the grain size range under $30 \mu \mathrm{m}$, because it mainly corresponds to the amount of $\varepsilon$ formed during cooling $^{(14)}$.

\section{Effect of austenite grain size on the morphology of $\varepsilon$ martensite}

Figure 4 represents the typical morphologies of $\varepsilon$ in the specimens with different austenite grain sizes. In a specimen annealed at $873 \mathrm{~K}$ (photograph (a)), only stacking faults which should be the nucleation site for the $\gamma-\varepsilon$ transformation $^{(15)(16)}$ were observed within small austenite grains of about $1 \mu \mathrm{m}$ (Type I). The larger the austenite grain size, the easier the formation of $\varepsilon$ becomes. Con-

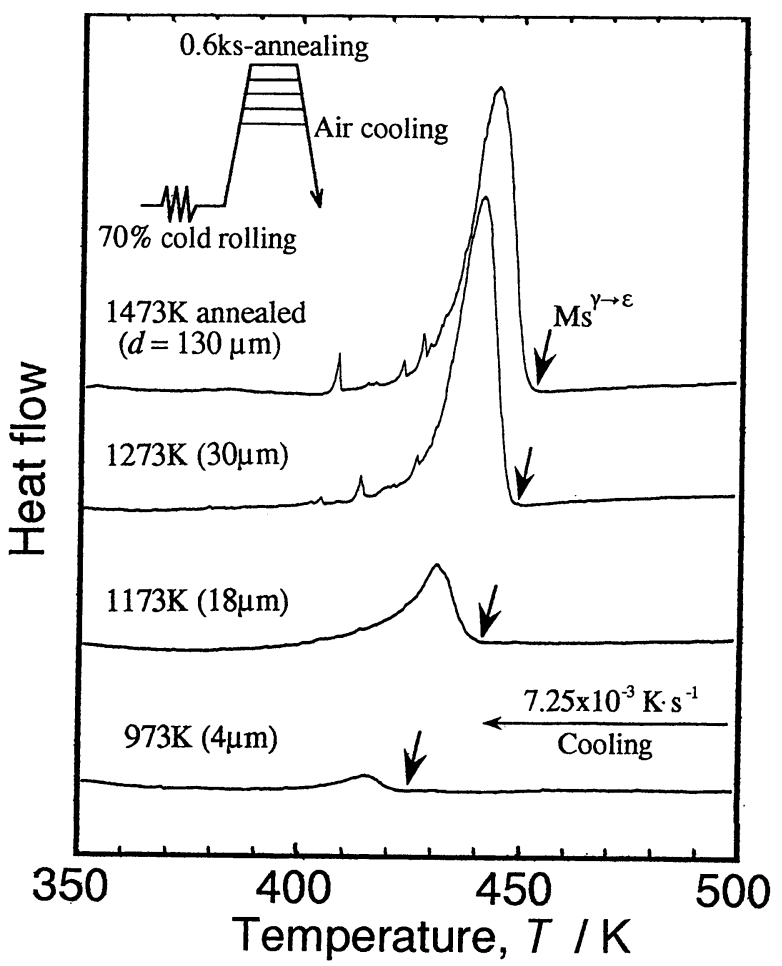

Fig. 3 DSC curves of Fe-15mass $\%$ Mn alloy with different austenite grain size of $4 \sim 130 \mu \mathrm{m} . M_{\mathrm{s}}^{\gamma \rightarrow \varepsilon}$ is the starting temperature of $\varepsilon$ martensitic transformation.
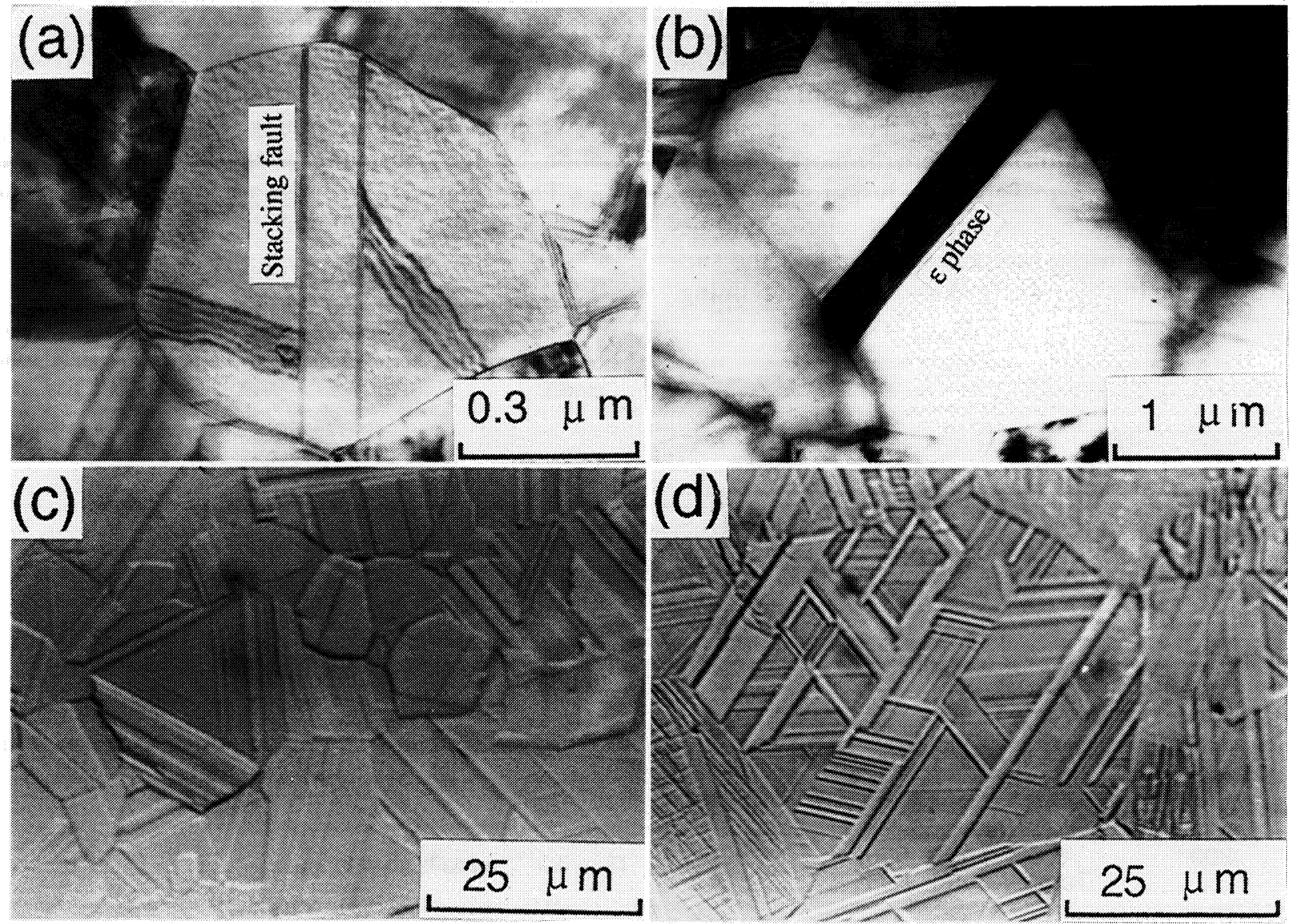

Fig. 4 Effect of austenite grain size on the morphology of $\varepsilon$ martensite in Fe-15mass\%Mn alloy. Annealed at (a) $873 \mathrm{~K}$, (b) $973 \mathrm{~K}$, (c) $1073 \mathrm{~K}$, and (d) $1273 \mathrm{~K}$ for $0.6 \mathrm{ks}$ after $70 \%$ cold-rolling. 


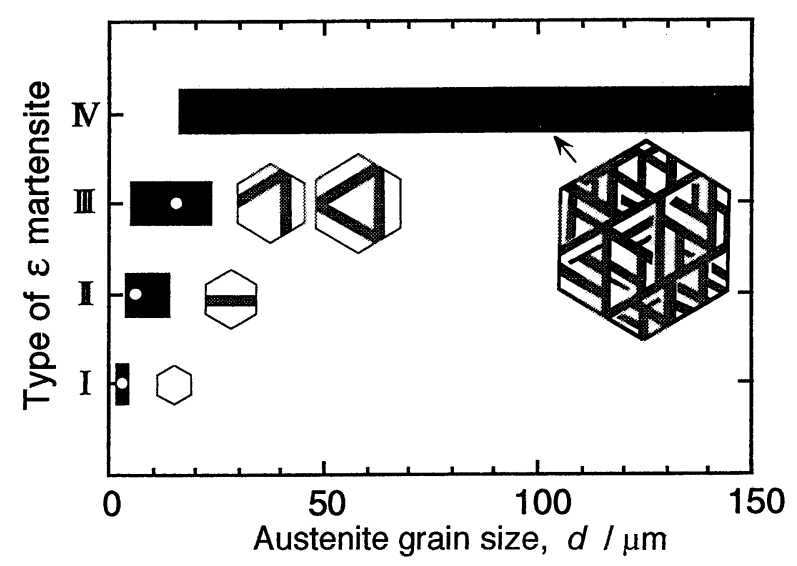

Fig. 5 Effect of austenite grain size on the type of $\varepsilon$ martensite morphology. Showing the region of austenite grain size where each type of $\varepsilon$ martensite was observed.

sidering the relation between austenite grain size and the morphology of $\varepsilon$, we can classify the characteristics of $\varepsilon$ as follows: One kind of $\varepsilon$ plates goes through an austenite grain from one boundary to the other of the opposite side (Type II, photograph (b)), several kinds of $\varepsilon$ plates with different growing directions are observed in one austenite grain and also they do not intersect each other within the grain (Type III, photograph (c)), and $\varepsilon$ plates complexly intersect each other within large austenite grains (Type IV, photograph (d)). Figure 5 summarizes the relation between austenite grain size and the morphology of $\varepsilon$ classified by the above five types. With refining austenite grain size, the morphology of $\varepsilon$ gradually changes from Type IV to Type II. Here, it should be noted that the critical grain size where the morphology of $\varepsilon$ changes from Type IV to Type III is just around $30 \mu \mathrm{m}$. This suggests that there is an important relationship between the change in the morphology of $\varepsilon$ and the suppressive effect in the $\gamma-\varepsilon$ transformation by grain refining.

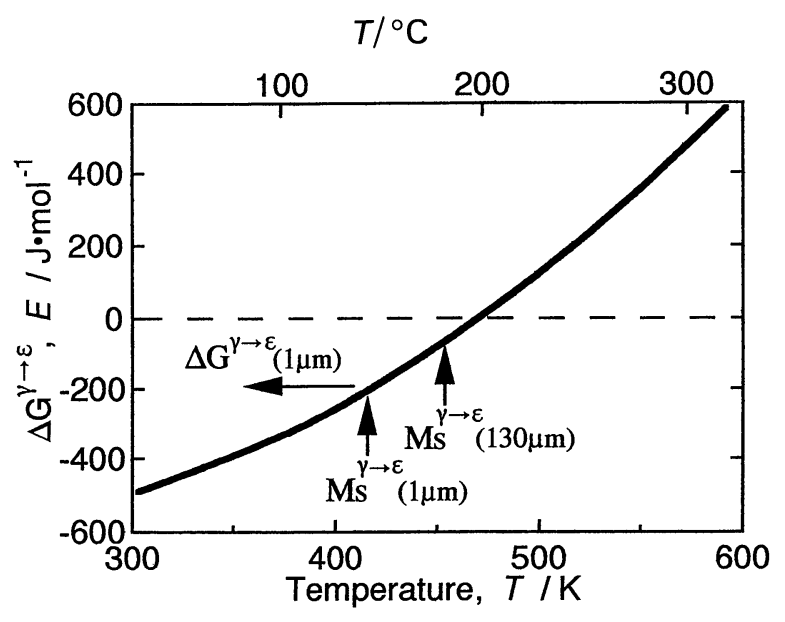

Fig. 6 Relation between temperature and the chemical free energy change for austenite to $\varepsilon$ martensite transformation in $\mathrm{Fe}-15 \mathrm{mass} \% \mathrm{Mn}$ alloy.

\section{Discussion}

\section{Thermodynamics in $\varepsilon$ martensitic transformation}

The effect of austenite grain refining on the $\gamma-\varepsilon$ transformation will be discussed thermodynamically in this section. Chemical free energy change between $\gamma$ and $\varepsilon$ $\left(\Delta G^{\gamma-\varepsilon}\right)$ in Fe-Mn binary alloy is dependent on the chemical compositions and temperature, and eq. $(3)^{\dagger}$ has been established on the basis of regular solution approximation $^{(17)-(19)}$.

$\Delta G^{\gamma-\varepsilon}=X_{\mathrm{Fe}} \Delta G_{\mathrm{Fe}}^{\gamma-\varepsilon}+X_{\mathrm{Mn}} \Delta G_{\mathrm{Mn}}^{\gamma-\varepsilon}+X_{\mathrm{Fe}} X_{\mathrm{Mn}} \Omega_{\mathrm{FeMn}}^{\gamma-\varepsilon}$

$X_{\mathrm{Fe}}, X_{\mathrm{Mn}}:$ atomic fraction

$\Delta G_{\mathrm{Fe}}^{\gamma-\varepsilon}, \Delta G_{\mathrm{Mn}}^{\gamma-\varepsilon}$ : free energy change between $\gamma$ and $\varepsilon$

$\Omega_{\mathrm{FeMn}}^{\gamma-\varepsilon}$ interaction parameter

Applying the values reported by Kaufman et al. ${ }^{(17)-(19)}$ into $\Delta G_{\mathrm{Fe}}^{\gamma-\varepsilon}, \Delta G_{\mathrm{Mn}}^{\gamma-\varepsilon}$ and $\Omega_{\mathrm{FeMn}}^{\gamma-\varepsilon}$, the free energy change $\Delta G^{\gamma-\varepsilon}$ in $\mathrm{Fe}-15 \mathrm{mass} \% \mathrm{Mn}$ alloy was given as a function of temperature, as shown in Fig. 6. Since the value of $\Delta G^{\gamma-\varepsilon}$ is negative below $455 \mathrm{~K}$, the transformation from $\gamma$ to $\varepsilon$ can occur thermodynamically at this temperature. Taking the driving force $(-90 \mathrm{~J} / \mathrm{mol})^{(6)}$ for the $\gamma-\varepsilon$ martensitic transformation into consideration, the $M_{s}^{\gamma-\varepsilon}$ is expected to be around $440 \mathrm{~K}$. It is well corresponding with that measured experimentally $(450 \mathrm{~K})$ for a specimen of large austenite grain size. When the suppressive effect in the $\gamma-\varepsilon$ transformation by grain refining is thought to be negligible for the specimen with the grain size of $130 \mu \mathrm{m}$, the free energy difference $\Delta G_{\text {be }}(\geq 0)$ estimated from the change in the $M_{\mathrm{s}}^{\gamma-\varepsilon}$ should represent the degree of suppressive effect by grain refining. Figure 7 indicates the relation between austenite grain size and the value of $\Delta G_{\text {be }}$. The driving force for the $\gamma-\varepsilon$ transformation $\left(\Delta G^{*}\right)$ must be described as follows:

$$
\Delta G^{*}=\Delta G^{\gamma-\varepsilon}+\Delta G_{\mathrm{be}}
$$

$\dagger$ The difference in the free energy between $\gamma$ and $\varepsilon\left(\Delta G^{\gamma \rightarrow \varepsilon}\right)$ in Fe-Mn binary alloys has been calculated in basis on a regular solution model.

$$
\begin{gathered}
G=H-T \cdot S+\Delta G^{\mathrm{E}} \\
\Delta G^{\mathrm{E}}: \text { Excess free energy } \\
H=X_{\mathrm{Fe}} H_{\mathrm{Fe}}+X_{\mathrm{Mn}} H_{\mathrm{Mn}} \\
H: \text { Enthalpy } \\
S=X_{\mathrm{Fe}} S_{\mathrm{Fe}}+X_{\mathrm{Mn}} S_{\mathrm{Mn}}+\Delta S_{\text {con. }} \\
S: \text { Entropy } \\
\Delta S_{\text {con. }}=-R\left(X_{\mathrm{Fe}} \ln X_{\mathrm{Fe}}+X_{\mathrm{Mn}} \ln X_{\mathrm{Mn}}\right) \\
\Delta S_{\text {con. }}: \text { Configuration entropy }
\end{gathered}
$$

By putting eqs. (2), (3) and (4) into eq. (1), eq. (1) is modified to eq. (5).

$$
G=X_{\mathrm{Fe}} G_{\mathrm{Fe}}+X_{\mathrm{Mn}} G_{\mathrm{Mn}}+\Delta G^{\mathrm{E}}+R T\left(X_{\mathrm{Fe}} \ln X_{\mathrm{Fe}}+X_{\mathrm{Mn}} \ln X_{\mathrm{Mn}}\right)
$$

$R$ : Gas constant

Thus, $\Delta G^{\nu \rightarrow \varepsilon}$ is finally given by eq. (6).

$$
\begin{aligned}
\Delta G^{\gamma \rightarrow \varepsilon}= & X_{\mathrm{Fe}} \Delta G_{\mathrm{Fe}}^{\gamma \rightarrow \varepsilon}+X_{\mathrm{Mn}} \Delta G_{\mathrm{Mn}}^{\gamma \rightarrow \varepsilon}+\Delta G^{\mathrm{E} \cdot \gamma}-\Delta G^{\mathrm{E} \cdot \varepsilon} \\
= & X_{\mathrm{Fe}} \Delta G_{\mathrm{Fe}}^{\gamma \rightarrow \varepsilon}+X_{\mathrm{Mn}} \Delta G_{\mathrm{Mn}}^{\gamma \rightarrow \varepsilon}+X_{\mathrm{Fe}} X_{\mathrm{Mn}} \Omega_{\mathrm{FeMn}}^{\gamma \rightarrow \varepsilon} \\
& \Omega_{\mathrm{FeMn}}^{\gamma \rightarrow \varepsilon} \text { Interaction parameter }
\end{aligned}
$$




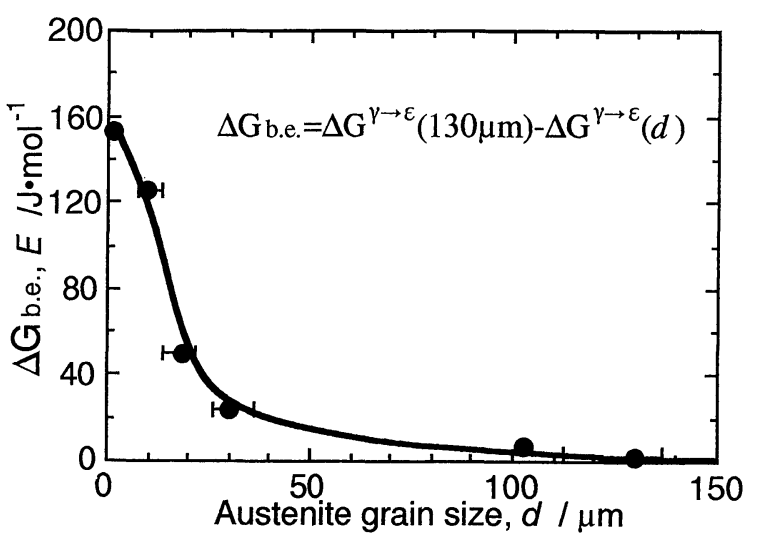

Fig. 7 Relation between austenite grain size and the chemical free energy change $\left(\Delta G_{\mathrm{be}}\right)$ as suppressive effect on $\varepsilon$ martensitic transformation. $\Delta G_{\mathrm{be}}$ was estimated from the decrement of $M_{\mathrm{s}}^{\gamma \rightarrow \varepsilon}$ with grain refining.

If we can presume that austenite could transform to $\varepsilon$ when $\Delta G^{*}$ exceeds $-90 \mathrm{~J} / \mathrm{mol}$, larger free energy $\Delta G^{\gamma-\varepsilon}$ will be required in case that the large suppressive effect $\Delta G_{\text {be }}$ was charged owing to fine austenite grains. As the result, the $M_{s}^{\gamma-\varepsilon}$ ought to be lowered in order to get larger free energy change. It should be noted, however, that the value of $\Delta G_{\text {be }}$ abruptly increases below $30 \mu \mathrm{m}$ with refining austenite grains and reaches the level over $150 \mathrm{~J} / \mathrm{mol}$ in the fine grain size range of around $1 \mu \mathrm{m}$. Comparison of this value with $90 \mathrm{~J} / \mathrm{mol}$ required for the $\gamma-\varepsilon$ transformation reveals the fact that the influence of austenite grain boundaries is very significant in the $\gamma-\varepsilon$ transformation.

\section{Crystallography in $\varepsilon$ martensitic transformation}

The suppressive effect in the $\gamma-\varepsilon$ transformation by grain refining will be discussed here in terms of the crystallography of $\gamma-\varepsilon$ transformation. Figure 8(a) shows the microstructure of a specimen annealed at $1173 \mathrm{~K}$ for $600 \mathrm{~s}$ after $70 \%$ cold rolling. The platelet structure observed within the matrix corresponds to $\varepsilon$ and we can find four kinds of $\varepsilon$ plate in the crystallographic nature, as indicated in the photograph. Figure 8(b) is the key diagram of a diffraction pattern obtained from the field of Fig. $8(a)$. In this case, the crystal plane is $\{110\}_{\gamma}$. Many observations were performed to determine the crystallographic nature of $\varepsilon$ plates, and the results show that four kinds of $\varepsilon$ plate; $(\overline{1} \overline{1} \overline{1})_{\gamma}[\overline{1} 2 \overline{1}]_{\gamma},(\overline{1} 11)_{\gamma}[\overline{1} \overline{2} 1]_{\gamma},(1 \overline{1} 1)_{\gamma}[\overline{2} \overline{1} 1]_{\gamma}$, and $(11 \overline{1})_{\gamma}[\overline{2} 1 \overline{1}]_{\gamma}$, in general $\{111\}_{\gamma}\langle 112\rangle_{\gamma}$, exist in the matrix. This relationship corresponds with that of ShojiNishiyama relation $^{(20)(21)}$. Consequently, four kinds of $\varepsilon$ plate on different $\{111\}_{\gamma}$ planes can be formed in one austenite grain. To the growth of $\varepsilon$ plates, Shockley partial dislocations might contribute ${ }^{(22)}$.

Contraction in the $c$-axis direction for the $\gamma$ - $\varepsilon$ transformation is about $0.7 \%{ }^{(23)}$ when the $c / a$ ratio of $\varepsilon$ structure is the theoretical value (1.633). However, the $c / a$ ratio determined by $\mathrm{X}$-ray diffraction analysis was a little bit smaller value (1.614), so that the contraction in the $c$-axis was estimated at about $1.16 \%$ in this study. Figure 9

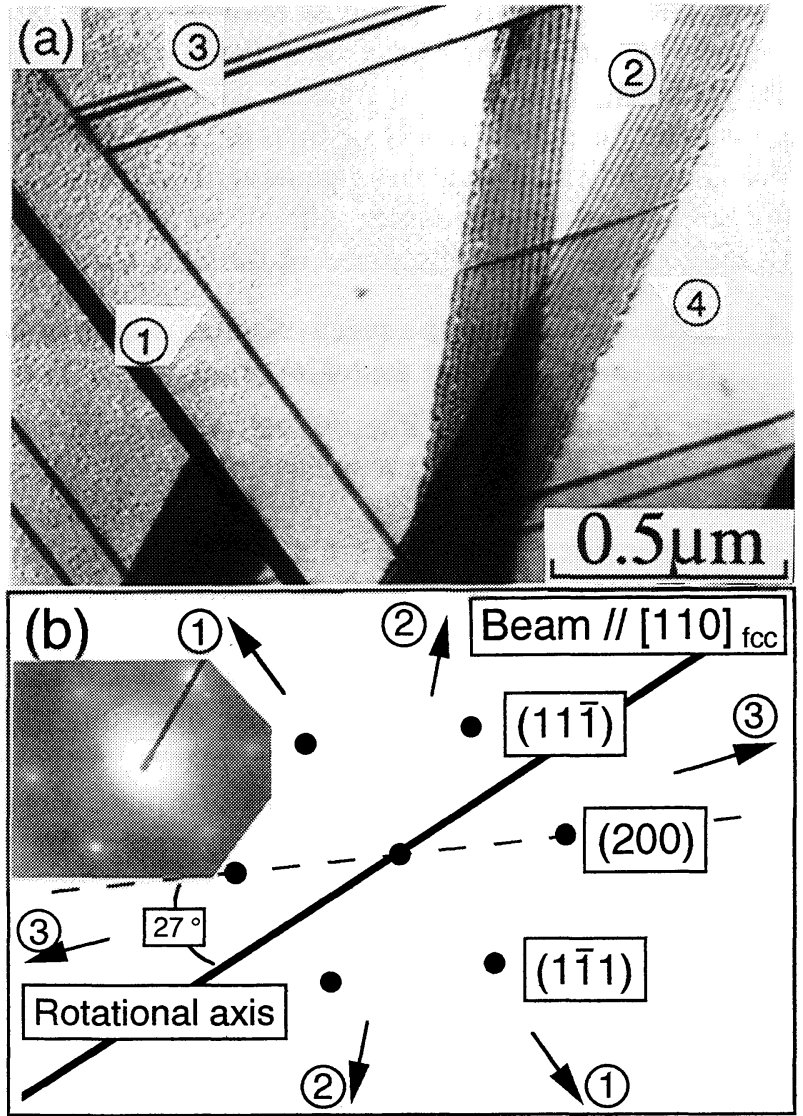

Fig. 8 Transmission electron micrograph (a) and diffraction pattern (b) of $\mathrm{Fe}-15 \mathrm{mass} \% \mathrm{Mn}$ alloy annealed at $1173 \mathrm{~K}$ for $0.6 \mathrm{ks}$ after $70 \%$ cold-rolling. Showing $\varepsilon$ plates formed in four directions.

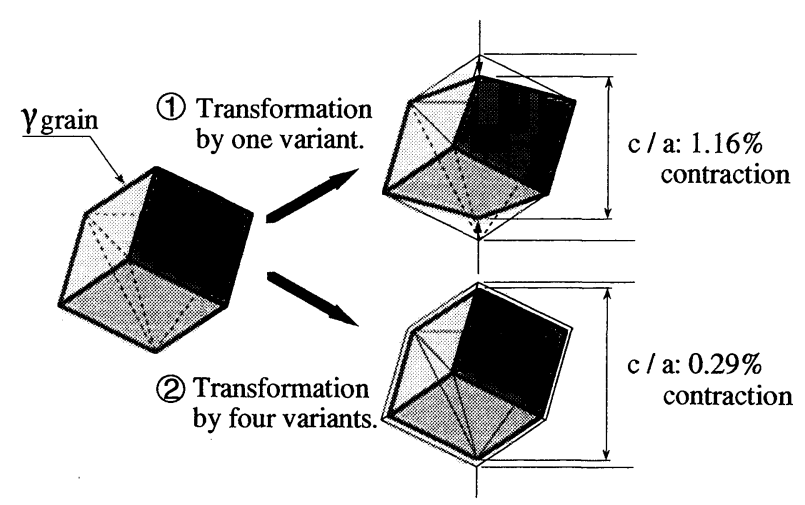

Fig. 9 Schematic illustration showing the difference in contraction caused by $\varepsilon$ martensitic transformation.

illustrates the models of contraction coarsed by $\gamma-\varepsilon$ transformation. If all of $\gamma$ transforms to $\varepsilon$ choosing only one way of four variants, an austenite grain contracts by $1.16 \%$ in one direction vertically against one of the $\{111\}_{\gamma}$ planes (1) in the figure). On the other hand, when austenite changes to $\varepsilon$ choosing all of four variants, an austenite grain contracts by $0.29 \%$ in the directions vertically against four $\{111\}_{y}$ planes (2) in the figure). Therefore, the latter case is much easier to occur than the former one, because the degree of local strain concentra- 
tion by the $\gamma-\varepsilon$ transformation is reduced in the latter case. Furthermore, when a lot of $\varepsilon$ plates with different lengths and thicknesses were formed at randam within a large austenite grain, the transformation strain might more effectively be dispersed in general. The reason why four kinds of $\varepsilon$ plate becomes difficult to form in small austenite grains will be discussed in the next section.

\section{Relation between the mechanism of $\varepsilon$ martensitic transformation and austenite grain size}

Figure 10 represents the microstructures of $\varepsilon$ plate that is just growing in a large austenite grain. Epsilon martensite usually nucleates around grain boundaries and grows toward inner side of austenite grain by "the branching of the $\varepsilon$ plate" as shown in optical micrograph (a), and finally forms the morphology classified by Type IV in Fig. 5. From TEM photograph (b), we can see that a different $\varepsilon$ plate grows toward another direction which must be parallel to one of the $\{111\}_{\gamma}$ planes. Although the detail mechanism on the branching of $\varepsilon$ plate was not cleared in this investigation, it is likely caused by the mechanism illustrated in Fig. 11. When the $\gamma-\varepsilon$ transformation proceeds by the stacking of a lot of stacking faults $^{(22)}$, the elastic stress at the tip of a growing $\varepsilon$ plate must be increased with thickening $\varepsilon$ plates, because the displacement coarsed by keeping the coherency between $\gamma$ and $\varepsilon$ structure is also increased in proportion to the
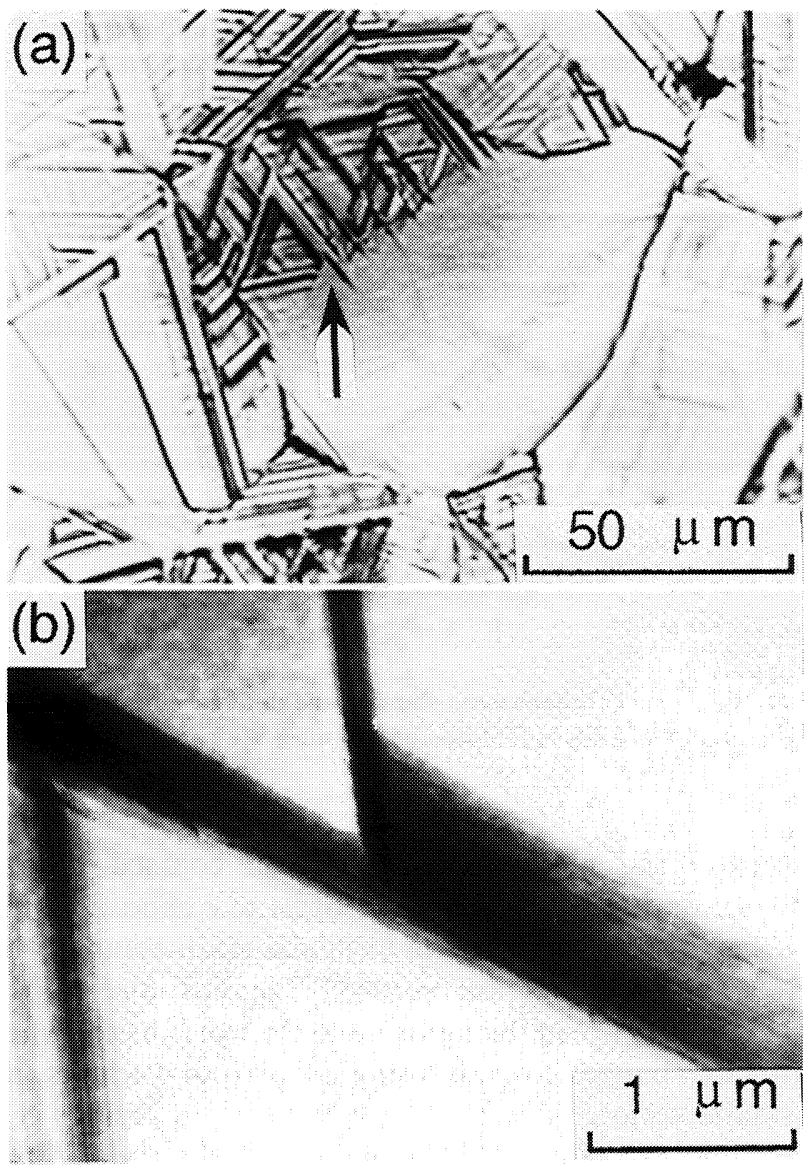

Fig. 10 Microstructures showing the branching of $\varepsilon$ martensite in $\mathrm{Fe}-15 \mathrm{mass} \% \mathrm{Mn}$ alloy annealed at $1323 \mathrm{~K}$ for $0.6 \mathrm{ks}$. (a) Grain boundary
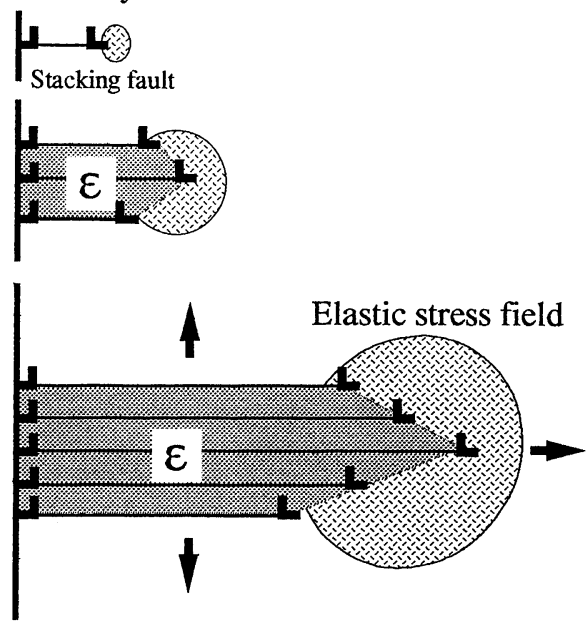

Grain boundary

(b)

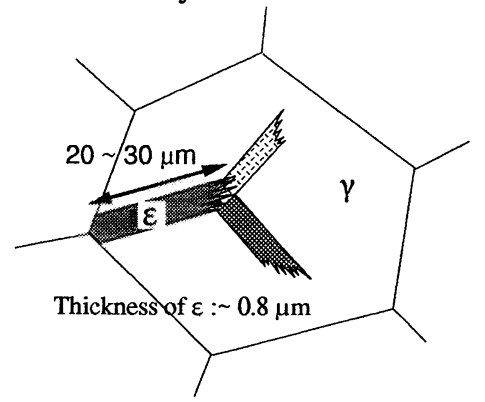

Fig. 11. Schematic illustration for $\varepsilon$ martensitic transformation.

thickness of $\varepsilon$ plates. Thus another $\varepsilon$ plate has to nucleate and grow on a different $\{111\}_{\gamma}$ plane in order to reduce the elastic stress at the tip of a pre-formed $\varepsilon$ plate, when $\varepsilon$ plates grow to a certain critical thickness and the elastic stress becomes large enough to make a new $\varepsilon$ plate nucleate. The critical thickness of $\varepsilon$ plates was estimated at around $0.8 \mu \mathrm{m}$ after many observations and the length of $\varepsilon$ plates grown to the critical thickness was about $20 \sim 30 \mu \mathrm{m}$ (the critical size for the branching of $\varepsilon$ plates). As the result, in case the size of austenite grains is large enough in comparison with the critical size, the branching of $\varepsilon$ plates is so easy to occur that the $\gamma-\varepsilon$ transformation can proceed smoothly with reducing the strain coarsed by the transformation. On the other hand, in case the size of austenite grain is not larger than the critical size, $\varepsilon$ plates formed around a grain boundary should meet the other boundary of opposite side before the branching, and finally forms the morphology classified as Type II or Type III. In these model, the chain reaction by the branching of $\varepsilon$ plates has been stopped owing to grain boundaries, so that $\gamma-\varepsilon$ transformation must markedly be suppressed by the refining of austenite grain size.

\section{Conclusion}

In $\mathrm{Fe}-15$ mass $\% \mathrm{Mn}$ binary alloy with the austenite grain size of $1 \sim 130 \mu \mathrm{m}$, the effect of grain refining on the behavior of the $\gamma-\varepsilon$ transformation and the morphology of $\varepsilon$ has been investigated. The results obtained are as 
follows:

(1) The amount of $\varepsilon$ formed athermally is decreased with refining austenite grains. Especially, the suppressive effect in $\gamma-\varepsilon$ transformation by grain refining was significant in the austenite grain size range below $30 \mu \mathrm{m}$.

(2) As the austenite grain size becomes larger, the microstructure within austenite grains changes in stratum: When the grain size is less than $30 \mu \mathrm{m}, \varepsilon$ plates go through austenite grains from one grain boundary to the other of the opposite side. When the grain size is sufficiently larger than $30 \mu \mathrm{m}$, however, a lot of $\varepsilon$ plates with different length and thickness intersect each other within austenite grains.

(3) In specimens with large austenite grains where a lot of $\varepsilon$ martensite plates can be formed within austenite grains, the $\varepsilon$ structure is composed of four variants of the $\varepsilon$ plate on $\{111\}_{\gamma}$ planes and they satisfy the ShojiNishiyama relation in the crystallographic nature.

(4) When an $\varepsilon$ plate grows to a certain critical size of around $30 \mu \mathrm{m}$, the branching of $\varepsilon$ takes place at the tip of a pre-formed $\varepsilon$ plate. In case the grain size is smaller than the critical size, such a chain reaction by the branching of $\varepsilon$ plates is stopped owing to grain boundaries. This leads to the suppressive effect in the $\gamma-\varepsilon$ transformation by austenite grain refining.

\section{Acknoledgment}

One of the authors (S.Takaki) greatly appreciate Prof. J. W. Morris Jr. (University of California, Berkeley) for giving him helpful suggestions on this work during his stay at Lawrence Berkeley Laboratory.

\section{REFERENCES}

(1) K. Tomimura, S. Takaki, S. Tanimoto and Y. Tokunaga: ISIJ International, 31 (1991), 721.
(2) T. Maki, Y. Tomota, I. Tamura: J. Jpn. Inst. Met., 38 (1974), 871.

(3) I. Tamura, T. Maki, M. Nakanishi and Y. Oka: Suiyokwaishi (Trans. Min. Metall. Assoc., Kyoto), 17 (1986), p. 75.

(4) Z. Nishiyama: Martensitic Transformations-Basic, Maruzen, (1971), p. 204.

(5) Y. Motohashi, K. Ohsawa, T. Hoshiya, Y. Okamoto, M. Ohmori: J. Jpn. Inst., Met., 55 (1991), 132.

(6) S. Ryufuku, Y. Tomota: Tech. Report, Ibaraki University, 34 (1986), 65.

(7) H. Otsuka, H. Yamada, T. Maruyama, H. Tanahashi, S. Matsuda and M. Murakami: ISIJ International, 30 (1990), 674.

(8) Y. Tomota, M. Strum and J. W. Morris, Jr: Met. Trans. A, 17A (1986), 537.

(9) H. Schumann: Arch Eisenhüttenwes., 38 (1967), 647.

(10) S. Takaki, S. Tanimoto, K. Tomimura, Y. Tokunaga: Tetsu-toHagané, 74 (1988), 112.

(11) S. Takaki, Y. Tokunaga, K. Tomimura: Tetsu-to-Hagané, 73 (1987), S539.

(12) M. Umemoto, I. Tamura: J. Jpn. Soc. Heat Treat., 24 (1984), 334.

(13) Y. Tomota: Tetsu-to-Hagané, 3 (1991), 315.

(14) Von Hans Keßler und Wolfgang Pitsch: Archiv fur das Eisenhüttenwesen, 39 (1968), 223.

(15) H. Fujita and S. Ueda: Acta Metall., 20 (1972), 759.

(16) J. W. Brooks, M. H. Loretto and R. E. Smallman: Acta Metall., 27 (1979), 1829, 1839.

(17) L. Kaufman and H. Bernstein: Computer Calculation of Phase Diagrams, Academic Press New York and London, (1970).

(18) K. Ishida and T. Nishizawa: J. Japan Inst. Metals, 36 (1972), 1238.

(19) L. D. Blackburm, L. Kaufman and M. Cohen: Acta Metall., 13 (1965), 533.

(20) H. Shoji: Zeits. Krist., 77 (1931), 381.

(21) Z. Nishiyama: Kinzoku-no-Kenkyu, 13 (1936), 300; Sci. Rep., Tohoku Imp. Univ., 25 (1936), 79.

(22) A. Sato, H. Sunaga and T. Mori: Proc. ICOMAT, Cambridge, Mass., American Inst. Metals, (1979), p. 183.

(23) Z. Nishiyama: Martensitic Transformations-Basic, Maruzen, (1971), p. 40. 